\title{
Identificação dos Fatores que Contribuem para Acidentes Envolvendo Ciclistas e Pedestres em uma Área Urbana ${ }^{1}$
}

\section{Identifying the Factors Contributing to Accidents Involving Cyclists and Pedestrians in an Urban Area}

\author{
Sousa, Pablo Brilhante de ${ }^{1}$; Lacerda, Diego Montenegro de ${ }^{2}$ \\ I Universidade Federal da Paraíba, Campus I - Centro de Tecnologia, João \\ Pessoa-PB, Brasil; pablo@ct.ufpb.br \\ 2 Universidade Federal da Paraíba, diego_lacerda17@hotmail.com
}

\begin{abstract}
RESUMO
Com o aumento da frota automobilística nos grandes centros urbanos no Brasil, o congestionamento tem sido um problema frequente na vida dos brasileiros. Os órgãos gestores têm se atentado para este fato e buscado solucioná-lo através do incentivo à utilização do transporte público e transportes não motorizados, como a bicicleta e as viagens a pé. Apesar de ser uma iniciativa extremamente positiva, é necessário que os usuários destes modos de transporte possam realizar seus trajetos de forma segura. Diversos são os registros de acidentes envolvendo ciclistas e pedestres nas grandes cidades. Com o intuito de obter informações acerca destes acidentes, este trabalho fez o levantamento de dados sobre a acidentalidade viária envolvendo os usuários de bicicletas e pedestres em João Pessoa-PB. A partir dos dados obtidos, tem-se a definição do local a ser estudado e, em seguida, a aplicação de formulário para obtenção de parâmetros que permitissem encontrar fatores contribuintes para acidentes de tráfego em uma área urbana. A partir desta investigação, foi identificada a prioridade de trechos que necessitam de melhorias por parte dos órgãos gestores municipais, atingindo os objetivos deste trabalho de iniciação científica desenvolvido na Universidade Federal da Paraíba.
\end{abstract}

Palavras-chave: Acidentalidade viária, ciclista, fatores contribuintes, pedestre.

\begin{abstract}
With the increase of the automobile fleet in the big urban areas in Brazil, the traffic jam has been a frequent problem in the life of the Brazilians. The management public agencies have been attempting to this fact and have tried to solve it by encouraging the use of public transport and alternative transport such as cycling and by foot. Although it is an extremely positive initiative, it is necessary that users of these modes of transportation can carry out their routes safely. There are several records of accidents involving cyclists and pedestrians in large cities. In order to obtain information about these accidents, this work surveys data on road accident involving bicycle and pedestrian users in João Pessoa-PB. Next, the parameters to be
\end{abstract}

${ }^{1}$ SOUSA, Pablo Brilhante de; LACERDA, Diego Montenegro de. Identificação dos Fatores que Contribuem para Acidentes envolvendo Ciclistas e Pedestres em uma Área Urbana. In: II SIMPÓSIO NACIONAL DE GESTÃO E ENGENHARIA URBANA: SINGEURB, 2019, São Paulo. Anais... Porto Alegre: ANTAC, 2019. 
analyzed in the on-site investigation were defined, in order to find contributing factors for traffic accidents. Finally, the results obtained in the field research are analyzed, pointing out the main points that need interference by the competent agencies, achieving the objectives of this scientific initiation work developed at the Federal University of Paraíba.

Keywords: Road safety, cyclist, pedestrian.

\section{INTRODUÇÃO}

A partir das diretrizes da Lei Federal N 12.587/2012 - Política Nacional de Mobilidade Urbana os municípios intensificaram a priorização, além do transporte coletivo, dos transportes não motorizados e, desta maneira, os estudos sobre acidentalidade viária tornaram-se de grande valia visto que, muitas vezes, a (in)segurança viária é considerada como um dos principais fatores que levam os usuários a preterirem as viagens a pé e de bicicleta em relação aos veículos automotivos que, reconhecidamente, possuem menor vulnerabilidade.

A segurança nas viagens é um fator que não pode ser negligenciado, principalmente, pelo fato de haver um grande número de indivíduos que realizam seus trajetos através de transportes não motorizados, como bicicleta ou a pé, nas áreas urbanas. Dada a fragilidade dos modos cicloviário e a pé, é fundamental que haja uma infraestrutura que possibilite os deslocamentos com o menor risco de ocorrência de acidentes. Além disso, segundo Sousa e Cunto (2018), por conta da sua importância, observa-se nos últimos anos cada vez mais estudos considerando a segurança viária como componente necessário ao planejamento de transportes.

Desta forma, a objetivo principal deste trabalho é a determinação de parâmetros que identifiquem os fatores que contribuem para a ocorrência de acidentes envolvendo pedestres e ciclistas em João Pessoa-PB. Para tanto, os objetivos específicos foram elencados:

- identificar, a partir de dados obtidos junto a SEMOB/JP - Secretaria de Mobilidade Urbana de João Pessoa-PB, os locais (bairros) com maior acidentalidade viária envolvendo pedestres e ciclistas na cidade. Para tanto, o mapeamento dos acidentes, em ambiente SIG, se faz necessário com o intuito de facilitar a visualização destes locais;

- definir parâmetros que possam influenciar na acidentalidade viária envolvendo pedestres e ciclistas a partir da revisão bibliográfica realizada;

- realizar um experimento, a partir dos bairros com maior acidentalidade viária, numa via urbana buscando, através dos parâmetros definidos, identificar os locais que necessitam de intervenção.

\section{SÍNTESE DO MÉTODO ELABORADO}

Com base na hipótese de que é possível identificar locais com acidentalidade viária envolvendo pedestres e ciclistas e levantar parâmetros que contribuem para a ocorrência de acidentes, foi proposto o método a seguir.

Na etapa de obtenção de dados, foi realizada uma revisão bibliográfica com o intuito de levantar fatores que influenciam na escolha dos modos não motorizados, além de características do transporte cicloviário e a pé, necessários para a compreensão dos parâmetros que influenciam na ocorrência de acidentes. Além disso, trabalhos que abordaram a acidentalidade viária, apresentando os fatores contribuintes para 0 acontecimento de acidentes, também foram consultados. 


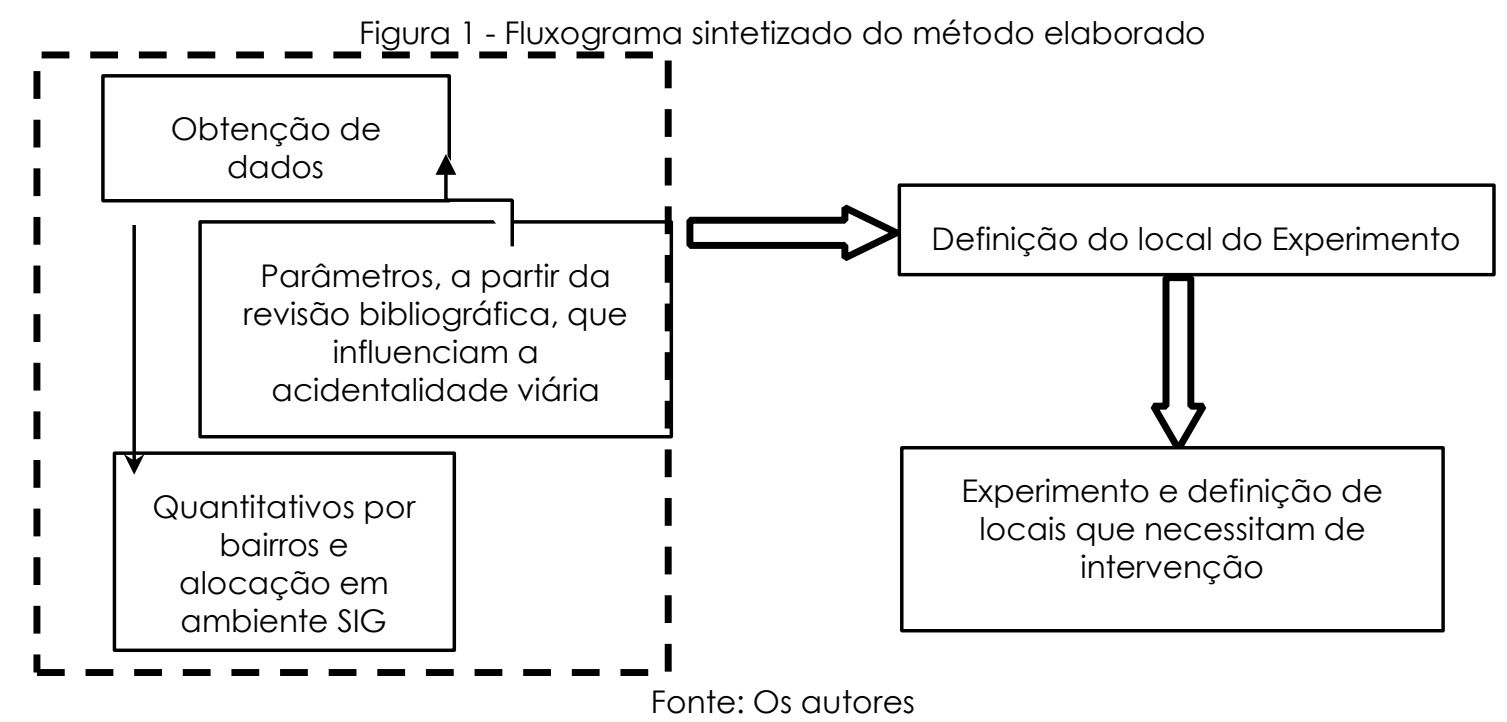

Paralelamente à revisão bibliográfica, foram obtidos os dados acerca de acidentes envolvendo pedestres e ciclistas, na cidade de João Pessoa-PB, junto ao órgão gestor de trânsito do município.

A partir das informações repassadas pela SEMOB-JP, foram desenvolvidos tabelas e mapas temáticos em SIG, com o intuito de identificar os bairros em que ocorreram acidentes envolvendo ciclistas e pedestres possibilitando, desta maneira, a seleção do local do experimento.

Após a definição do local, foi realizado o experimento numa via que deveria apresentar, reconhecidamente, alto fluxo de bicicletas e pedestres, além dos acidentes registrados. Foi elaborado um formulário com o objetivo de preencher as informações relacionadas aos parâmetros definidos na etapa de obtenção de dados necessários à pesquisa. Por fim, identificado os pontos críticos, sugere-se o(s) trecho(s) que necessita (m) de intervenção com maior urgência.

\section{EXPERIMENTO}

A escolha do local a ser analisado foi feita a partir das séries históricas disponibilizadas pela SEMOB/JP. A Tabela 1 apresenta os bairros com maior incidência de acidentes envolvendo ciclistas entre 2010 e 2014.

De forma semelhante, fez-se a organização dos dados de forma a obter os bairros nos quais houve o maior número de acidentes envolvendo pedestres entre os anos de 2012 e 2016 . Estes dados estão apresentados na Tabela 2.

A partir das Tabelas 1 e 2, em que foram identificados os números de ocorrências registradas tanto para ciclistas quanto para pedestres, foi possível determinar o bairro Mangabeira como a área a ser estudada. Vale ressaltar que o estudo foi realizado considerando o número absoluto de acidentes. Apesar de ser importante, esta não é a melhor alternativa. O ideal seria utilizar números relativos, como frequência de acidentes dividida pela população ou número de acidentes pela frota que trafega na via. No entanto, não havia dados suficientes para que fosse realizada a análise considerando estes parâmetros. 
Tabela 1 - Bairros com maior número de acidentes envolvendo ciclistas

\begin{tabular}{|c|c|}
\hline Bairro & Número de acidentes envolvendo ciclistas \\
\hline Mangabeira & 236 \\
\hline Valentina & 157 \\
\hline Cristo redentor & 143 \\
\hline Mandacaru & 143 \\
\hline
\end{tabular}

Tabela 2 - Bairros com maior número de acidentes envolvendo pedestres

\begin{tabular}{c|c}
\hline Bairro & $\begin{array}{c}\text { Número de acidentes envolvendo } \\
\text { pedestres }\end{array}$ \\
\hline Mangabeira & 438 \\
\hline Centro & 304 \\
\hline Cruz das armas & 226 \\
\hline Valentina & 178 \\
\hline \multicolumn{2}{c|}{ Fonte: SEMOB-JP adaptado pelo(s) autor(es) (2017) }
\end{tabular}

\subsection{Descrição do bairro "Mangabeira"}

A Figura 2, retirada da digitalização com o uso de SIG, apresenta a localização do bairro na cidade de João Pessoa-PB.

Figura 2 - Bairros de João Pessoa-PB

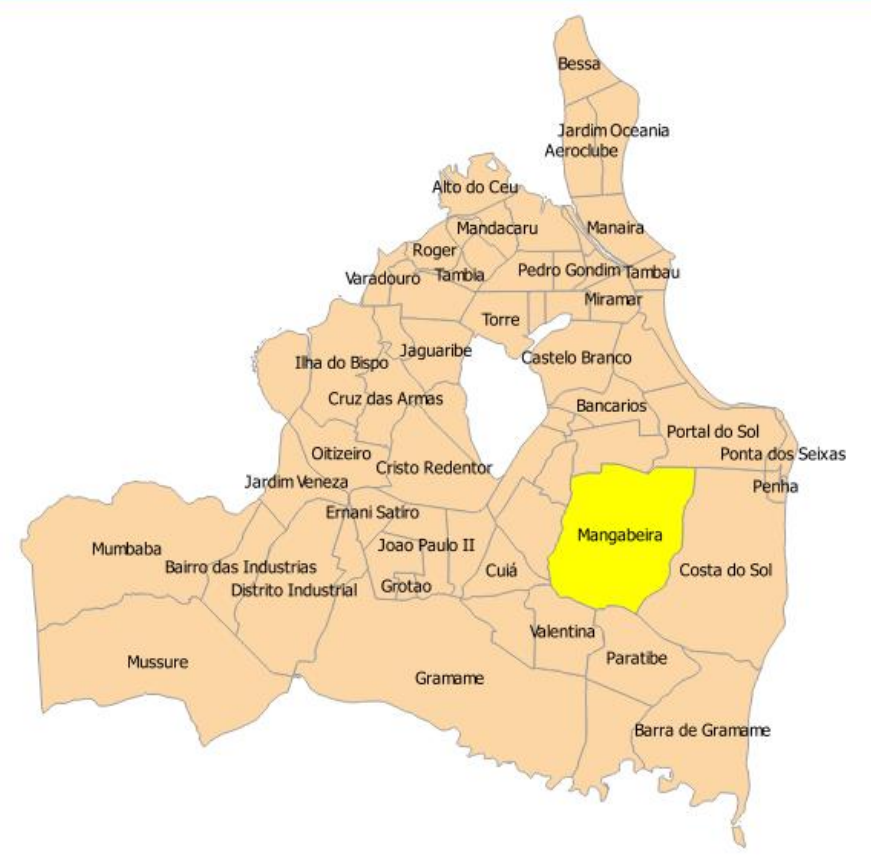

Fonte: SEMOB-JP adaptado pelo(s) autor(es) (2017)

A população de Mangabeira, segundo o Censo realizado pelo IBGE em 2010, é de 75.988 habitantes, sendo 35.844 homens e 40.144 mulheres. Desta forma, o bairro é composto $47,17 \%$ por homens e 52,83\% de mulheres. Com isto, segundo o IBGE (2010), caracteriza-se como o bairro mais populoso da cidade, constituindo assim uma importante área de concentração populacional.

A área territorial do bairro de Mangabeira é de $10,79 \mathrm{~km}^{2}$ de extensão e apresenta uma densidade populacional de $7.462,78 / \mathrm{km}^{2}$. Segundo a pesquisa domiciliar do IBGE do ano de 2010, Mangabeira se caracteriza como um bairro denso e populoso (SILVA, 2013). 


\subsection{Definição da via urbana}

De posse dos dados de acidentes no bairro de Mangabeira, foi feito o mapeamento de forma a alocar os acidentes por rua, localizando-os no centro do logradouro. Este mapeamento foi executado com auxílio da ferramenta computacional QGis (Quantum GIS).

A via escolhida para a realização do experimento de segurança viária, que apresentou maior número absoluto de acidentes envolvendo ciclistas e pedestres nas séries históricas disponibilizadas, foi a Avenida Josefa Taveira, uma das principais avenidas do bairro.

A extensão total da via é de aproximadamente $1,8 \mathrm{~km}$, segundo o Google Earth, e considerada uma das principais ruas do bairro, sendo importante na circulação entre os bairros de Valentina e Bancários. O uso e ocupação do solo ao longo da via é principalmente comercial, com diversos tipos de estabelecimentos. Quanto ao sistema de trânsito, a via apresenta 04 (quatro) faixas de tráfego, sendo duas em cada sentido (uma delas exclusiva para ônibus).

A via escolhida foi dividida em 03 (três) trechos em sequência (1, 2 e 3), de tamanhos idênticos, e o método aplicado em toda a sua extensão.

\subsection{Parâmetros analisados}

Como um dos objetivos específicos do trabalho foi a identificação dos locais que necessitam de maior urgência de interferência dos órgãos gestores, o enfoque do experimento surgiu a partir dos fatores viário-ambientais citados por Chagas (2011) e mostrados na Tabela 3.

O estado de superfície da pista de rolamento está relacionado com as condições vigentes de trafegabilidade da via. Uma superfície que se encontra escorregadia, com possibilidade de derrapagem, possui um alto risco associado à ocorrência de acidentes. Desta forma, observar a qualidade da superfície da pista de rolamento e intervir, em caso de estado de conservação inadequado, é fundamental para diminuir a acidentalidade viária.

O estado de superfície da calçada também possui influência, pois desníveis acentuados e pisos derrapantes podem ocasionar uma mudança de trajeto do pedestre e, dependendo da decisão tomada, aumentar os riscos de acidentes. No formulário, para as superfícies da pista e da calçada, havia valores variando de 1 a 5 , sendo 1 mais íntegro e 5 o mais falho. Para este fator, foi observada a superfície considerando presença de areia, grama, valas e outros elementos que podem contribuir para a ocorrência de acidentes.

Tabela 3 - Parâmetros utilizados na investigação

\begin{tabular}{|c|c|}
\hline \multicolumn{2}{|c|}{ Parâmetros escolhidos para investigação } \\
\hline Estado da superfície da via & Velocidade na via \\
\hline Estado da superfície da calçada & Obstáculos permanentes \\
\hline Pintura & Obstáculos temporários \\
\hline Tachão & Drenagem \\
\hline Sinalização vertical na interseção & Conflitos \\
\hline Sinalização horizontal na interseção & Estado psicofísico \\
\hline Sinalização na parada de ônibus & lluminação \\
\hline
\end{tabular}

Os elementos: pintura, tachões, sinalização vertical e horizontal em interseções, sinalização de parada de ônibus e de velocidade na via, a informação foi coletada pela visualização da presença ou não e, em caso de desgaste, considerada como não presente.

Obstáculos permanentes e temporários fazem com que o usuário da via mude sua direção, podendo ocasionar acidentes. Obstruções na calçada são preocupantes, uma vez que, pode obrigar o pedestre a ter que se deslocar pela pista de rolamento, aumentando sua suscetibilidade a ocorrência de acidentes. No formulário, os permanentes foram considerados 
como árvores, placas de trânsito, poste, parada de ônibus e outros elementos que estão presentes de forma contínua na calçada. Já os temporários foram carros estacionados, baldes de lixo, placas de comércio e outros elementos que estavam dificultando o trajeto de pedestres.

Para drenagem, estado psicofísico e iluminação, o preenchimento do formulário foi o simples cômputo da contagem de elementos de drenagem ("bocas de lobo"), de estabelecimentos que comercializam bebidas alcoólicas e do número de postes em cada trecho, respectivamente.

Por fim, no formulário, foi contabilizado o número de conflitos de tráfego em cruzamentos em cada trecho. Quanto mais pontos de conflitos, maior o risco de acidentes.

\subsection{Resultados}

Para determinar o local mais crítico, verificou-se a pior situação para cada parâmetro, identificando o trecho que possuiu maior deficiência em cada categoria analisada, através do cômputo simples. O trecho 2, localizado no intervalo correspondente ao centro da via, apresentou maior deficiência em sete parâmetros dentre os quatorze analisados e, desta forma, foi considerado como prioritário na escolha de melhorias a serem feitas pelos órgãos gestores do município. Salienta-se que o trecho 2 apresenta um supermercado de grande porte agravando, ainda mais, a situação de risco ao qual estão sujeitos ciclistas e pedestres na via em análise.

A Figura 3 ilustra uma montagem de 02 imagens do trecho crítico 2. Do lado esquerdo notase a faixa de pedestres em péssimo estado. Já do lado direito, há um cruzamento sem qualquer tipo de sinalização.

Figura 3 - Imagens do trecho crítico 2 em 2017

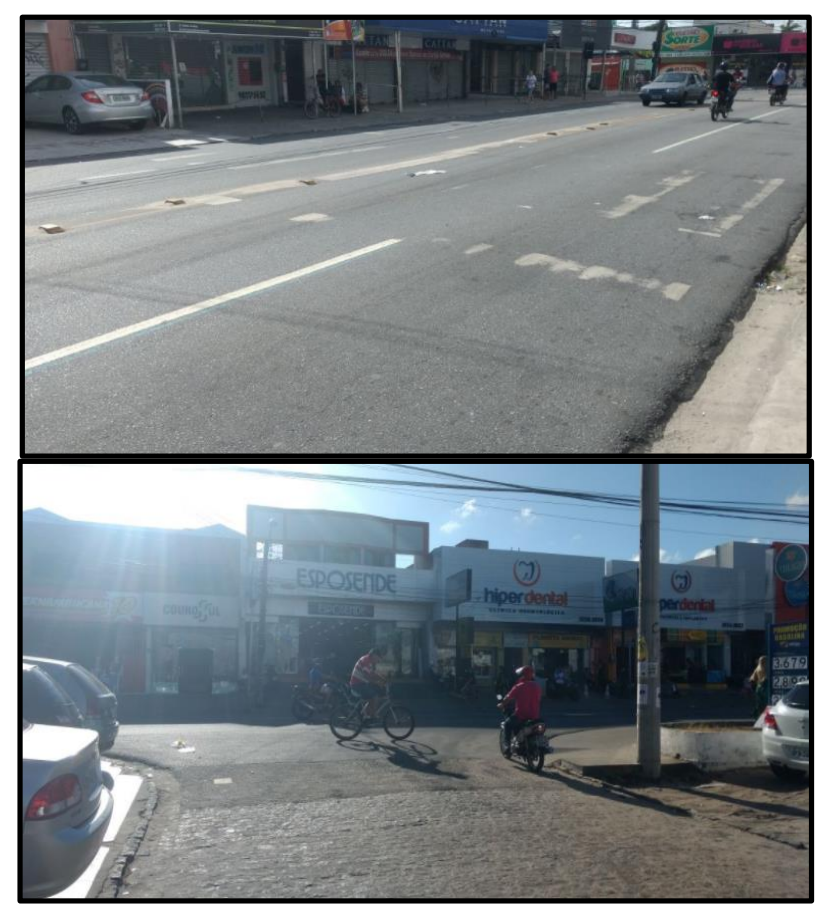

Fonte: Os autores

\section{CONCLUSÕES}

O presente trabalho identificou inicialmente o bairro com maior número de ocorrência de acidentes envolvendo ciclistas e pedestres na cidade de João Pessoa-PB. Em seguida, foi selecionada a avenida neste bairro que teve maior acidentalidade viária envolvendo a soma de acidentes dos usuários citados, neste caso, a Avenida Josefa Taveira. Com a aplicação da técnica de investigação, foi possível identificar os locais que necessitam de intervenção 
por parte dos órgãos competentes para a diminuição do risco de ocorrência de acidentes no local.

Desta forma, como os objetivos propostos foram atingidos, visto que a determinação de parâmetros que identifiquem os fatores que contribuem para a ocorrência de acidentes envolvendo pedestres e ciclistas em uma área urbana foram obtidos, sugere-se que o método possa ser replicado em outros locais e, desta forma, servir como ferramenta de melhoria do sistema viário e de trânsito de cidades.

\section{AGRADECIMENTOS}

À Universidade Federal da Paraíba pela oportunidade de desenvolvimento do trabalho de iniciação científica em 2017.

\section{REFERÊNCIAS}

BRASIL. Lei Federal $n^{\circ}$ 12.587, de 3 de janeiro de 2012. Política Nacional de Mobilidade Urbana.

CHAGAS, D. M. (2011) Estudo sobre Fatores Contribuintes de Acidentes de Trânsito Urbano. Dissertação de Mestrado. Universidade Federal do Rio Grande do Sul, Rio Grande do Sul, RS.

SILVA, P. A. M. (2013) Bairro de Mangabeira: Um Subcentro Urbano na Cidade de João Pessoa/PB. Monografia de Bacharelado em Geografia. Universidade Federal da Paraíba, João Pessoa, PB.

SOUSA, F. F. L. M.; CUNTO, F. J. C. (2018) Desempenho da Segurança Viária na Modelagem Integrada do Uso do Solo e Transporte - Estudo de Caso: Fortaleza 2040. Revista Transportes, Vol. 26, N 4, ISSN: 2237-1346. 